\title{
RECICLAGEM DE REFRATÁRIOS DE CARRO TORPEDO E PLACA GAVETA NA USIMINAS*
}

\author{
Marco Antônio Quintela ${ }^{1}$ \\ Epitácio Pessoa Ponce de Lion² \\ Roselaine Gonçalves Magalhães ${ }^{3}$
}

\section{Resumo}

São apresentados e discutidos os resultados de estudos de pesquisa para o desenvolvimento de prática para reciclagem de sucata refratária na Usiminas. $\mathrm{O}$ processo contempla a obtenção de agregados a partir do beneficiamento, por meio de britagem e classificação granulométrica, de tijolos de carro torpedo e placa gaveta após utilização industrial. Os agregados reciclados são adicionados em concretos refratários de alto desempenho. Os resultados de testes laboratoriais indicaram que os agregados podem ser incorporados com sucesso a concretos para canal de corrida. Essa prática tem sido amplamente utilizada para otimizar a manutenção e melhorar o desempenho ambiental.

Palavras-chave: Reciclagem; Concreto; Refratário.

\section{REFRACTORY RECYCLING FROM TORPEDO CAR AND SLIDING GATE PLATE AT USIMINAS}

\section{Abstract}

Research results for the development of refractory recycling practices at Usiminas are presented and discussed. The process involves crushing, sieving and grain size classification of used refractories, such as torpedo car brick and sliding gate plate. The recycled aggregates are incorporated in castables for blast furnace trough. Laboratory results indicated that the aggregates can be successfully added in castables. This practice has been widely used for optimizing the maintenance and improving the environmental performance.

Keywords: Recycling; Castable; Refractory.

Engenheiro Mecânico, M.Sc., MBA; Centro de Tecnologia Usiminas; Ipatinga, MG, Brasil.

2 Engenheiro Siderúrgico; Assessor Executivo, Gerência de Integração de Áreas Primárias, Usiminas; Ipatinga, MG, Brasil.

3 Técnica em Química; Centro de Tecnologia Usiminas; Ipatinga, MG, Brasil.

\footnotetext{
* Contribuição técnica ao 44 Seminário de Redução de Minério de Ferro e Matérias-primas, 15은 Simpósio Brasileiro de Minério de Ferro e 2 Simpósio Brasileiro de Aglomeração de Minério de Ferro, 15 a 18 de setembro de 2014, Belo Horizonte, MG, Brasil.
} 


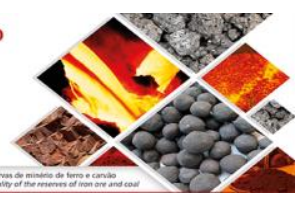

\section{INTRODUÇÃO}

Até o final dos anos 90, grande parte dos refratários após utilização industrial (sucata refratária) era destinada a aplicações secundárias, tais como: condicionamento de escória, pavimentação de rodovias e aterro. Ao longo dos últimos anos, os esforços de pesquisa e desenvolvimento da siderurgia e da indústria de refratários proporcionaram soluções econômicas e ambientalmente viáveis para reciclagem de sucata refratária. No Japão, essas atividades tiveram início, de forma estruturada, há mais de uma década. Uma fração considerável da sucata refratária tem sido utilizada com sucesso em aplicações nobres, por exemplo, matérias-primas para refratários [1-3].

$\mathrm{Na}$ Usiminas, os esforços para aproveitamento de sucata refratária remontam aos anos 80 com o beneficiamento (britagem e classificação granulométrica) de tijolos de MgO-C após emprego industrial. Os agregados obtidos eram utilizados na produção de tijolos para panelas de aço. A partir dos anos 90, a tecnologia para aproveitamento de sucata refratária em concreto ganhou grande impulso. Recentemente, foi desenvolvida a prática para reciclagem de agregados obtidos de placa gaveta, que tem se mostrado atrativa e segura.

Nesse contexto, são apresentados e discutidos os resultados de propriedades físicas e químicas de concreto ligado por sílica coloidal, modificado a partir da incorporação de agregados reciclados de tijolos de carro torpedo e placa gaveta. Os resultados animadores desse desenvolvimento, o apelo ecológico e as vantagens econômicas estimularam a implementação dessa prática nas usinas da Usiminas.

\section{MATERIAIS E MÉTODOS}

Foi investigado, por meio de testes laboratoriais, o desempenho de quatro composições de concreto do sistema $\mathrm{Al}_{2} \mathrm{O}_{3}-\mathrm{SiC}-\mathrm{C}$, ligado a sílica coloidal, contendo $10 \%$ de agregados reciclados (tabela 1 ).

Tabela 1. Composições de concreto do sistema $\mathrm{Al}_{2} \mathrm{O}_{3}-\mathrm{SiC}-\mathrm{C}$ para canal de corrida modificadas a partir da adição de agregados reciclados.

\begin{tabular}{l|l}
\hline \multicolumn{2}{|c}{ Composições } \\
\hline 0 & Concreto isento de agregado \\
\hline 1 & Concreto com $10 \%$ de agregado de placa (4 mm a $18 \mathrm{~mm})$ \\
\hline 2 & Concreto com $10 \%$ de agregado de tijolo de torpedo $(4 \mathrm{~mm}$ a $18 \mathrm{~mm})$ \\
\hline 3 & $\begin{array}{l}\text { Concreto com } 10 \% \text { de agregado de placa }(80 \% \text { de } 4 \mathrm{~mm} \text { a } 18 \mathrm{~mm} \text { e } 20 \% \text { de } 1 \mathrm{~mm} \\
\text { a } 6 \mathrm{~mm})\end{array}$ \\
\hline 4 & Concreto com $10 \%$ de agregado de placa $(1 \mathrm{~mm}$ a $6 \mathrm{~mm})$ \\
\hline
\end{tabular}

Os agregados foram obtidos a partir do beneficiamento de tijolos de carro torpedo $\left(\mathrm{Al}_{2} \mathrm{O}_{3}-\mathrm{SiC}-\mathrm{C}\right)$ e placas gaveta $\left(\mathrm{Al}_{2} \mathrm{O}_{3}-\mathrm{SiO}_{2}-\mathrm{C}+\mathrm{ZrO}_{2}\right)$ após utilização industrial. $\mathrm{O}$ processo contempla britagem, separação magnética para remoção da fração metálica e classificação granulométrica dos agregados (figura 1).

A contaminação do agregado por escória e outros agentes representa um problema potencial. Normalmente, as fases indesejáveis concentram-se nas frações mais finas dos agregados de tijolos de carro torpedo, por exemplo, abaixo de $4 \mathrm{~mm}$. Diferentemente, a placa gaveta apresenta baixo grau de contaminação. Por essa

\footnotetext{
* Contribuição técnica ao 44 Seminário de Redução de Minério de Ferro e Matérias-primas, 15은 Simpósio Brasileiro de Minério de Ferro e 2 Simpósio Brasileiro de Aglomeração de Minério de Ferro, 15 a 18 de setembro de 2014, Belo Horizonte, MG, Brasil.
} 


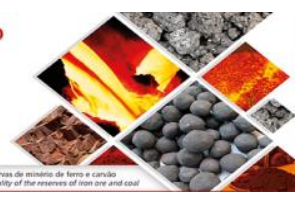

razão, o estudo explorou também o potencial de reciclagem de agregados mais finos de placa gaveta (acima de $1 \mathrm{~mm}$ ).

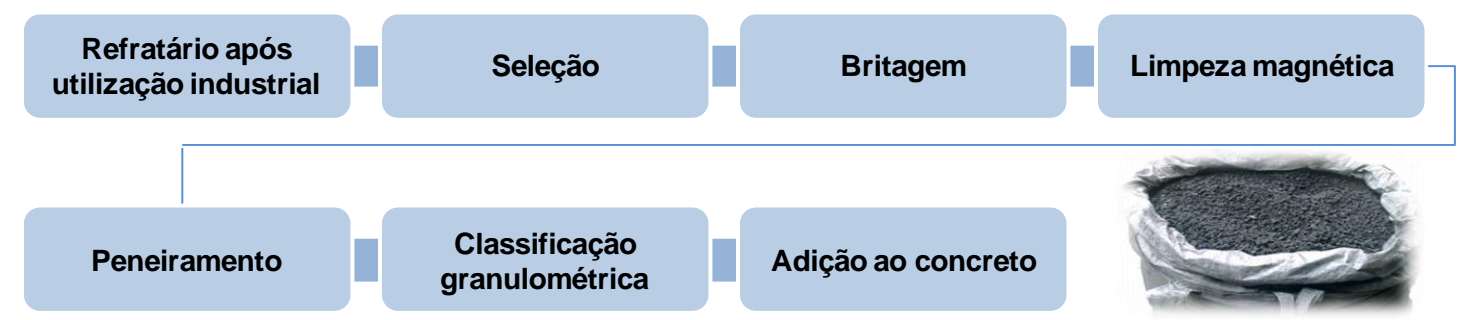

Figura 1. Processo para reciclagem de tijolos de carro torpedo e placa gaveta na Usiminas.

\subsection{Análise Química}

A quantidade de ferro total nas diferentes frações granulométricas dos agregados foi determinada por meio de análise química por espectrometria de plasma. O intuito dessas análises é investigar os efeitos de eventual contaminação (ferro) nas propriedades das composições.

\subsection{Segregação do Concreto}

O método de teste desenvolvido na Usiminas permite determinar a segregação do concreto provocada pela adição de agregados reciclados. O experimento empregou forma metálica de $100 \mathrm{~mm}$ de diâmetro por $500 \mathrm{~mm}$ de altura dividida em cinco segmentos. As composições foram previamente misturadas a seco durante 2 min. Posteriormente, a sílica coloidal ( $9 \%$ em peso) foi adicionada de forma gradual. A mistura foi mantida por mais 4 min no misturador em alta rotação, vertida na forma $e$ submetida à vibração por $10 \mathrm{~min}$. Imediatamente, foram retiradas da forma três camadas de $70 \mathrm{~mm}$ de altura de concreto, referentes às regiões superior, intermediária e inferior, para análise granulométrica a úmido (peneiras de $4 \mathrm{~mm}$, $2 \mathrm{~mm}, 1 \mathrm{~mm}$ e $0,21 \mathrm{~mm})$.

\subsection{Variação Linear Dimensional}

O comportamento dimensional das composições foi determinado em corpos de prova de $40 \mathrm{~mm} \times 40 \mathrm{~mm} \times 160 \mathrm{~mm}$ após coqueificação a $1200^{\circ} \mathrm{C}$ e $1400^{\circ} \mathrm{C}$ durante $5 \mathrm{~h} \mathrm{[4]}$

\subsection{Resistência à Flexão a Temperatura Ambiente}

A resistência à flexão foi medida em corpos de prova de $40 \mathrm{~mm} \times 40 \mathrm{~mm} \times 160 \mathrm{~mm}$ após secagem a $110^{\circ} \mathrm{C}$ por $24 \mathrm{~h}$ e coqueificação a $1000^{\circ} \mathrm{C}$ e $1400^{\circ} \mathrm{C}$ durante $5 \mathrm{~h}[5]$.

\subsection{Resistência à Flexão a Quente}

A resistência à flexão a quente foi determinada nas temperaturas de $1200^{\circ} \mathrm{C}$ e $1400^{\circ} \mathrm{C}$, em atmosfera de nitrogênio, com encharque de $30 \mathrm{~min}$. O teste foi efetuado em corpos-de-prova de $25 \mathrm{~mm} \times 25 \mathrm{~mm} \times 150 \mathrm{~mm}$ coqueificados nas respectivas temperaturas durante $5 \mathrm{~h}[6]$.

* Contribuição técnica ao 44 Seminário de Redução de Minério de Ferro e Matérias-primas, $15^{\circ}$ Simpósio Brasileiro de Minério de Ferro e 2 Simpósio Brasileiro de Aglomeração de Minério de Ferro, 15 a 18 de setembro de 2014, Belo Horizonte, MG, Brasil. 


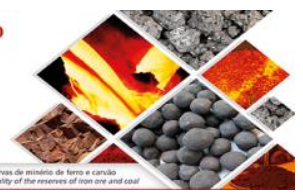

\subsection{Resistência ao Choque Térmico}

O experimento consistiu em aquecer subitamente uma das superfícies dos corpos de prova de $40 \mathrm{~mm} \times 40 \mathrm{~mm} \times 160 \mathrm{~mm}$ por meio de chama de maçarico. Foram efetuados 20 ciclos consecutivos de aquecimento e resfriamento ao ar ambiente.

\subsection{Ataque por Escória}

A resistência ao ataque por escória foi determinada por meio de ensaios realizados em forno rotativo, entre $1550^{\circ} \mathrm{C}$ e $1600^{\circ} \mathrm{C}$, em corpos-de-prova de seção trapezoidal nas dimensões de $(88 \mathrm{~mm} ; 68 \mathrm{~mm}) \times 30 \mathrm{~mm} \times 190 \mathrm{~mm}$. Foi utilizada escória típica de alto-forno [7].

\section{RESULTADOS E DISCUSSÃO}

\subsection{Análise Química}

$\mathrm{Na}$ figura 2, é mostrada a distribuição de ferro total nas diferentes frações granulométricas dos agregados. A concentração máxima de ferro $(1,44 \%)$ foi observada na fração mais fina do agregado de placa. A quantidade de ferro reduziu de forma significativa para as amostras relativas ao agregado de $4,00 \mathrm{~mm}$ a $6,35 \mathrm{~mm}$. Entretanto, não se espera efeito importante, mesmo para 1,44 \% de ferro, no desempenho das composições, uma vez que as matérias-primas do concreto contêm baixo teor de ferro $\left(\mathrm{Fe}_{2} \mathrm{O}_{3}=0,30 \%\right)$.

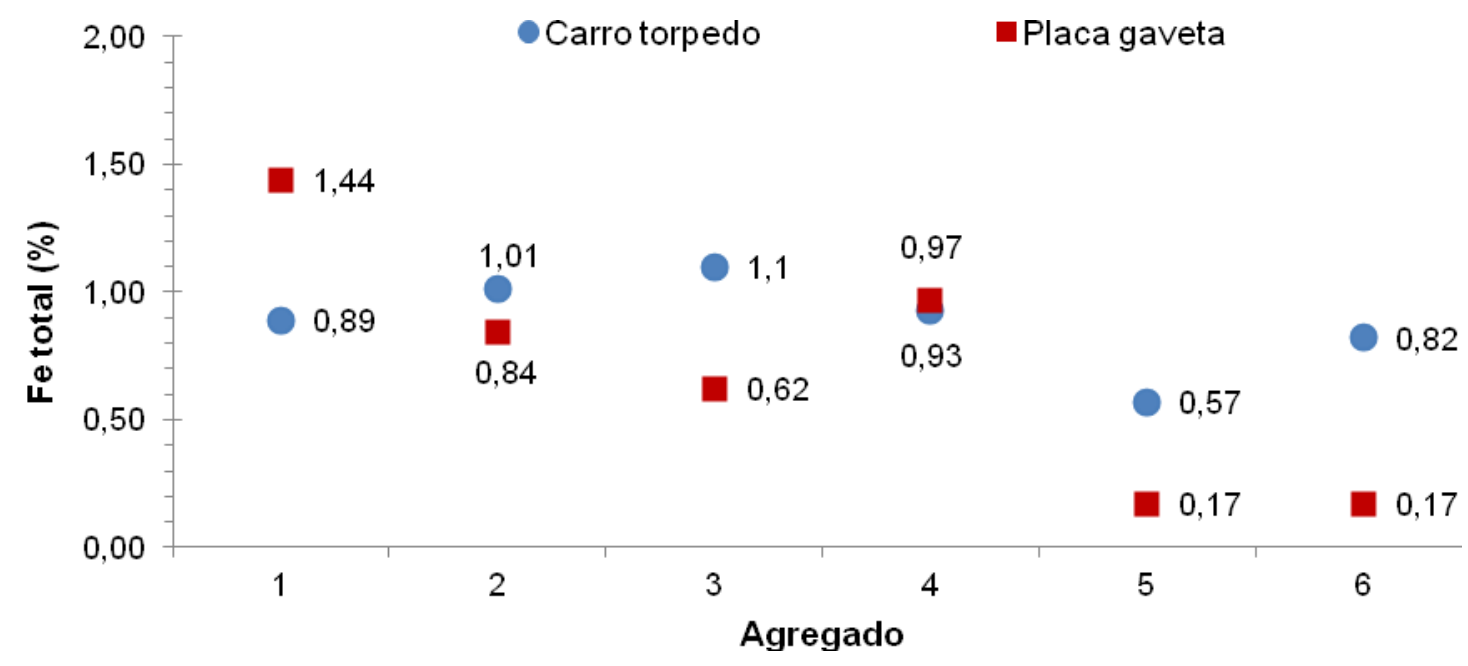

\begin{tabular}{l|l}
\hline 1 - menor que $1,00 \mathrm{~mm}$ & 2 - maior que $1,00 \mathrm{~mm}$ e menor que $2,00 \mathrm{~mm}$ \\
\hline 3 - maior que $2,00 \mathrm{~mm}$ e menor que $3,36 \mathrm{~mm}$ & 4 - maior que $3,36 \mathrm{~mm}$ e menor que $4,00 \mathrm{~mm}$ \\
\hline 5 - maior que $4,00 \mathrm{~mm}$ e menor que $5,66 \mathrm{~mm}$ & 6 - maior que $5,66 \mathrm{~mm}$ e menor que $6,35 \mathrm{~mm}$ \\
\hline
\end{tabular}

Figura 2. Distribuição de ferro total nas frações dos agregados de carro torpedo e placa gaveta.

\subsection{Segregação do Concreto}

A segregação resulta da propensão ao escoamento descendente de partículas mais densas e de maior massa durante bombeamento e aplicação do concreto. Esse

\footnotetext{
* Contribuição técnica ao 44 Seminário de Redução de Minério de Ferro e Matérias-primas, 15ㅇ Simpósio Brasileiro de Minério de Ferro e $2^{\circ}$ Simpósio Brasileiro de Aglomeração de Minério de Ferro, 15 a 18 de setembro de 2014, Belo Horizonte, MG, Brasil.
} 


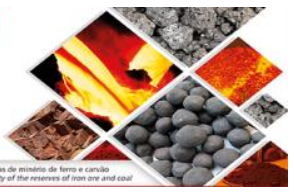

comportamento, embora atípico, compromete as propriedades físicas e químicas do refratário devido ao gradiente de propriedades.

Os resultados do experimento para simular a segregação indicaram que o concreto com adição de $10 \%$ de agregado de placa $(80 \%$ de $4 \mathrm{~mm}$ a $18 \mathrm{~mm}$ e $20 \%$ de $1 \mathrm{~mm}$ a $6 \mathrm{~mm}$ ) apresentou comportamento homogêneo, ou seja, não houve segregação da fração grossa (figura 3). As camadas inferior, intermediária e superior exibiram composição granulométrica semelhante. A quantidade de sílica coloidal também não apresentou variação substancial. $O$ teor de líquido da camada inferior correspondeu a $4,4 \%$, o da camada intermediária a $4,6 \%$ e o da camada superior a $4,4 \%$. A suspensão de sílica coloidal contém $40 \%$ em peso de $\mathrm{SiO}_{2}$. Assim, a quantidade de líquido introduzida foi equivalente a $5,4 \%$, para $9 \%$ de sílica coloidal na mistura. A diferença $(0,8 \%$ ou $1,0 \%)$ foi atribuída à solução necessária para molhar a superfície do misturador, impeller e forma.

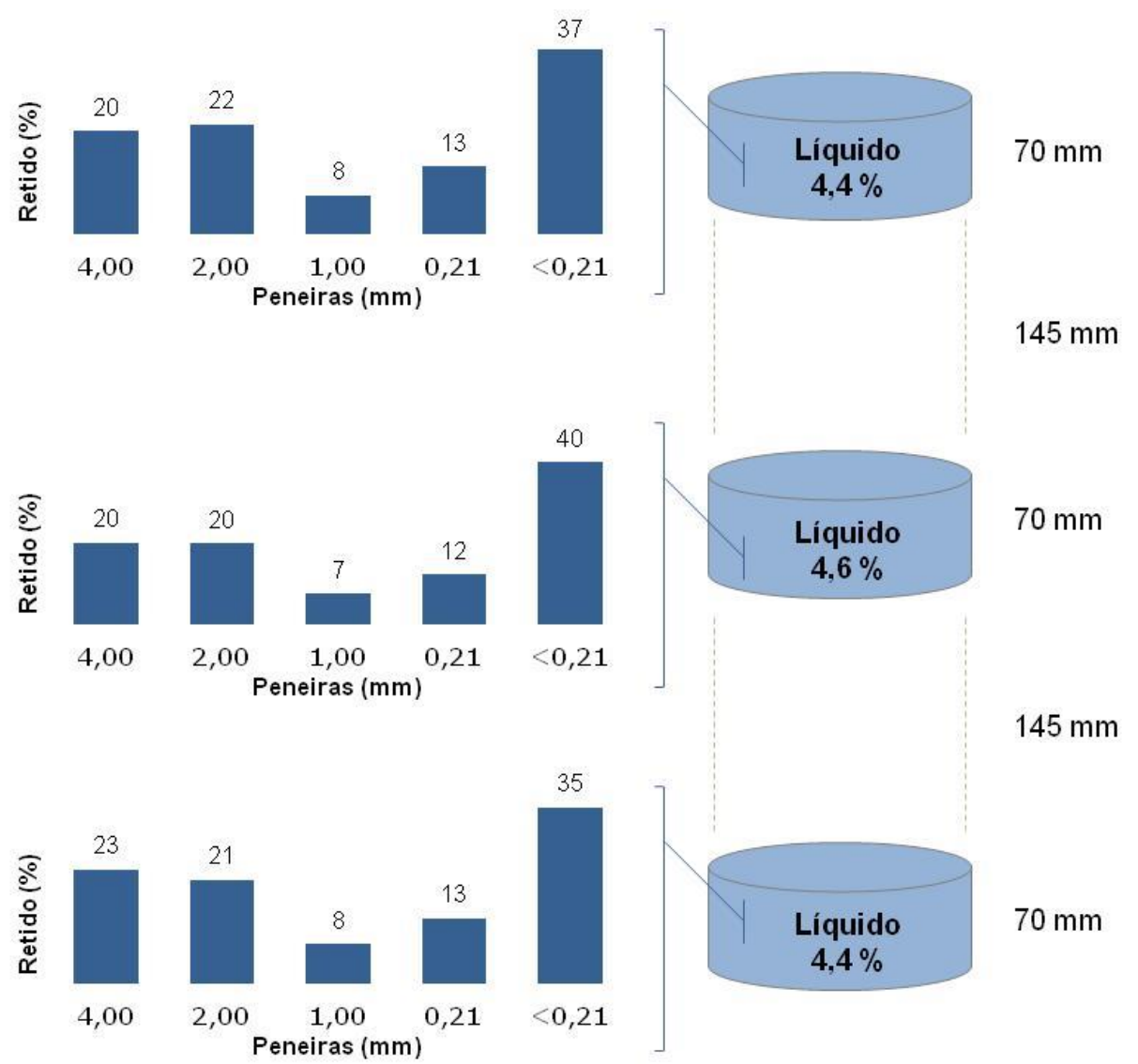

Figura 3. Distribuição granulométrica do concreto com $10 \%$ de agregado de placa ( $80 \%$ de $4 \mathrm{~mm}$ a $18 \mathrm{~mm}$ e $20 \%$ de $1 \mathrm{~mm}$ a $6 \mathrm{~mm}$ ) após experimento para avaliar a segregação.

\subsection{Variação Linear Dimensional}

$\mathrm{Na}$ figura 4, são mostrados os valores de variação linear dimensional após coqueificação a $1200^{\circ} \mathrm{C}$ e $1400^{\circ} \mathrm{C}$ durante $5 \mathrm{~h}$. Os resultados indicaram que não houve modificação significativa nas dimensões após coqueificação a $1200^{\circ} \mathrm{C}$. Já os corpos de prova coqueificados a $1400^{\circ} \mathrm{C}$ exibiram pequena expansão. A variação linear ou volumétrica positiva e controlada do concreto é vantajosa para inibir a formação de trincas transversais no canal de corrida.

* Contribuição técnica ao $44^{\circ}$ Seminário de Redução de Minério de Ferro e Matérias-primas, $15^{\circ}$ Simpósio Brasileiro de Minério de Ferro e 2 Simpósio Brasileiro de Aglomeração de Minério de Ferro, 15 a 18 de setembro de 2014, Belo Horizonte, MG, Brasil. 


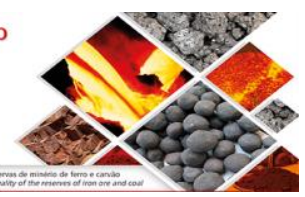

Com relação às composições, não houve modificação significativa da variação linear dimensional com a adição de agregados.

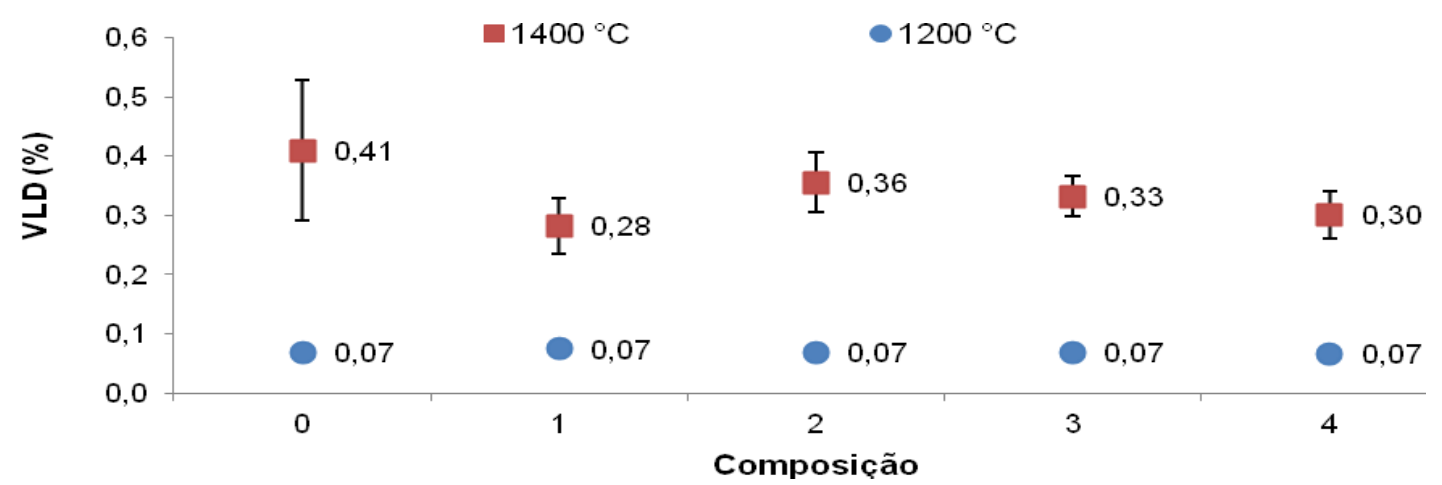

Figura 4. Variação linear dimensional após coqueificação a $1200^{\circ} \mathrm{C} e 1400{ }^{\circ} \mathrm{C}\left(\overline{\mathrm{x}} \pm \sigma_{\mathrm{n}-1}\right)$.

\subsection{Resistência à Flexão a Temperatura Ambiente}

Os resultados mostraram que a coqueificação $\left(1000^{\circ} \mathrm{C}\right.$ ou $\left.1400^{\circ} \mathrm{C}\right)$ proporcionou acréscimo substancial na resistência à flexão a temperatura ambiente (figura 5). Além disso, a incorporação de $10 \%$ de agregados reciclados ao concreto não afetou de forma significativa a resistência à flexão.

$\mathrm{O}$ ensaio após secagem a $110^{\circ} \mathrm{C}$ visou simular a resistência adquirida pelas composições após aplicação e cura industrial. Os resultados dos testes efetuados em amostras coqueificadas a $1000^{\circ} \mathrm{C}$ e $1400^{\circ} \mathrm{C}$ permitiram inferir sobre o maior ou menor grau de dificuldade na remoção (corte) do concreto durante reparo do canal.

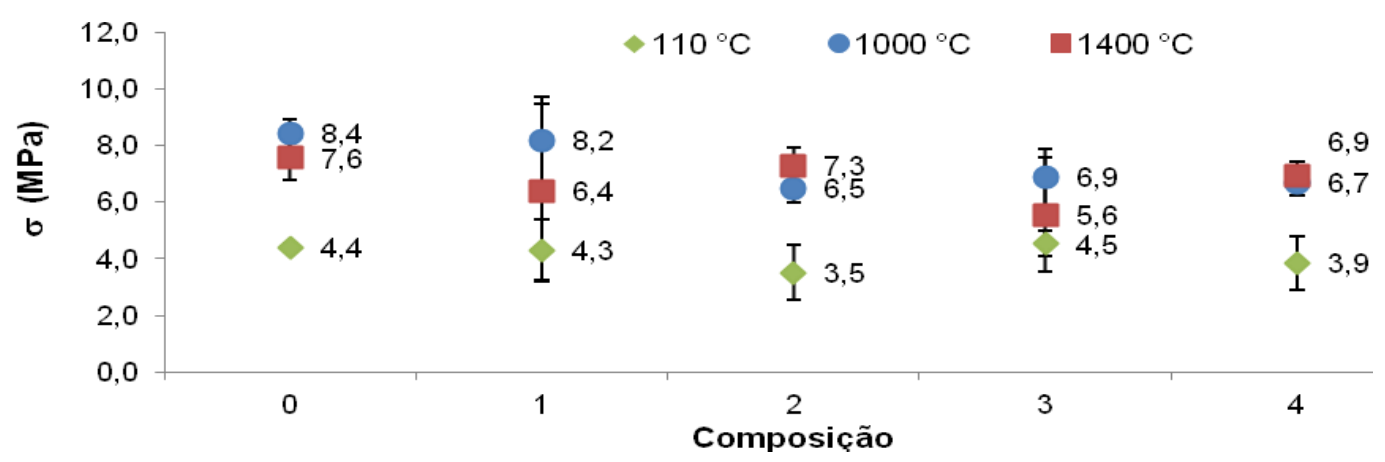

Figura 5. Resistência à flexão a temperatura ambiente das composições após secagem a $110^{\circ} \mathrm{C}$ e coqueificação a $1000^{\circ} \mathrm{C}$ e $1400^{\circ} \mathrm{C}\left(\bar{x} \pm \sigma_{n-1}\right)$.

\subsection{Resistência à Flexão a Quente}

$\mathrm{Na}$ figura 6, são mostrados os valores de resistência à flexão nas temperaturas de $1200^{\circ} \mathrm{C}$ e $1400^{\circ} \mathrm{C}$. Os resultados indicaram que a resistência mecânica reduziu significativamente com a temperatura. Esse comportamento decorre dos efeitos negativos de fases de menor refratariedade que atuam na matriz do concreto. Contudo, a adição de agregados ao concreto não comprometeu a resistência mecânica a quente, principalmente em temperatura mais elevada $\left(1400^{\circ} \mathrm{C}\right)$. A composição 2, que contém agregado de carro torpedo, exibiu menor valor médio de resistência à flexão a $1400^{\circ} \mathrm{C}$.

\footnotetext{
* Contribuição técnica ao 44 Seminário de Redução de Minério de Ferro e Matérias-primas, 15은 Simpósio Brasileiro de Minério de Ferro e 2ํ Simpósio Brasileiro de Aglomeração de Minério de Ferro, 15 a 18 de setembro de 2014, Belo Horizonte, MG, Brasil.
} 
Redução de Minério de Ferro

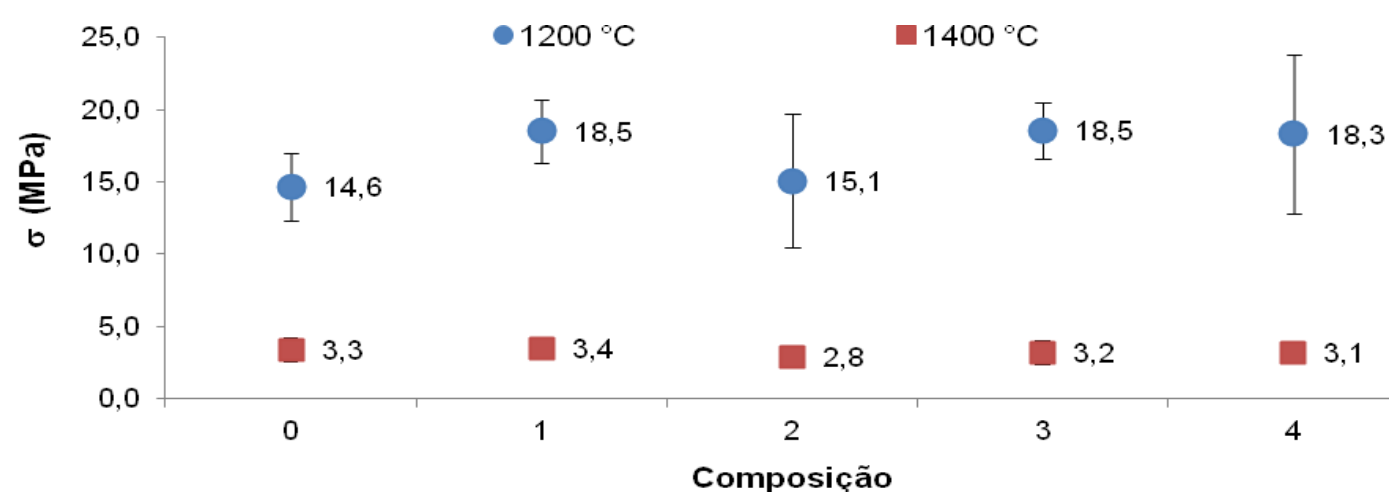

Figura 6. Resistência à flexão das composições nas temperaturas de $1200^{\circ} \mathrm{C}$ e $1400^{\circ} \mathrm{C}\left(\overline{\mathrm{x}} \pm \sigma_{\mathrm{n}-1}\right)$.

A preservação da resistência mecânica a quente para as diferentes composições forneceu indicativo da elevada refratariedade dos agregados e concordou com os valores relativamente baixos de ferro total nos agregados reciclados.

\subsection{Resistência ao Choque Térmico}

Os resultados mostraram que a adição de agregados reciclados não afetou a resistência ao dano por choque térmico (figura 7). A baixa densidade de trincas dos corpos de prova indicou que não houve dano severo mesmo após 20 ciclos de aquecimento e resfriamento ao ar.

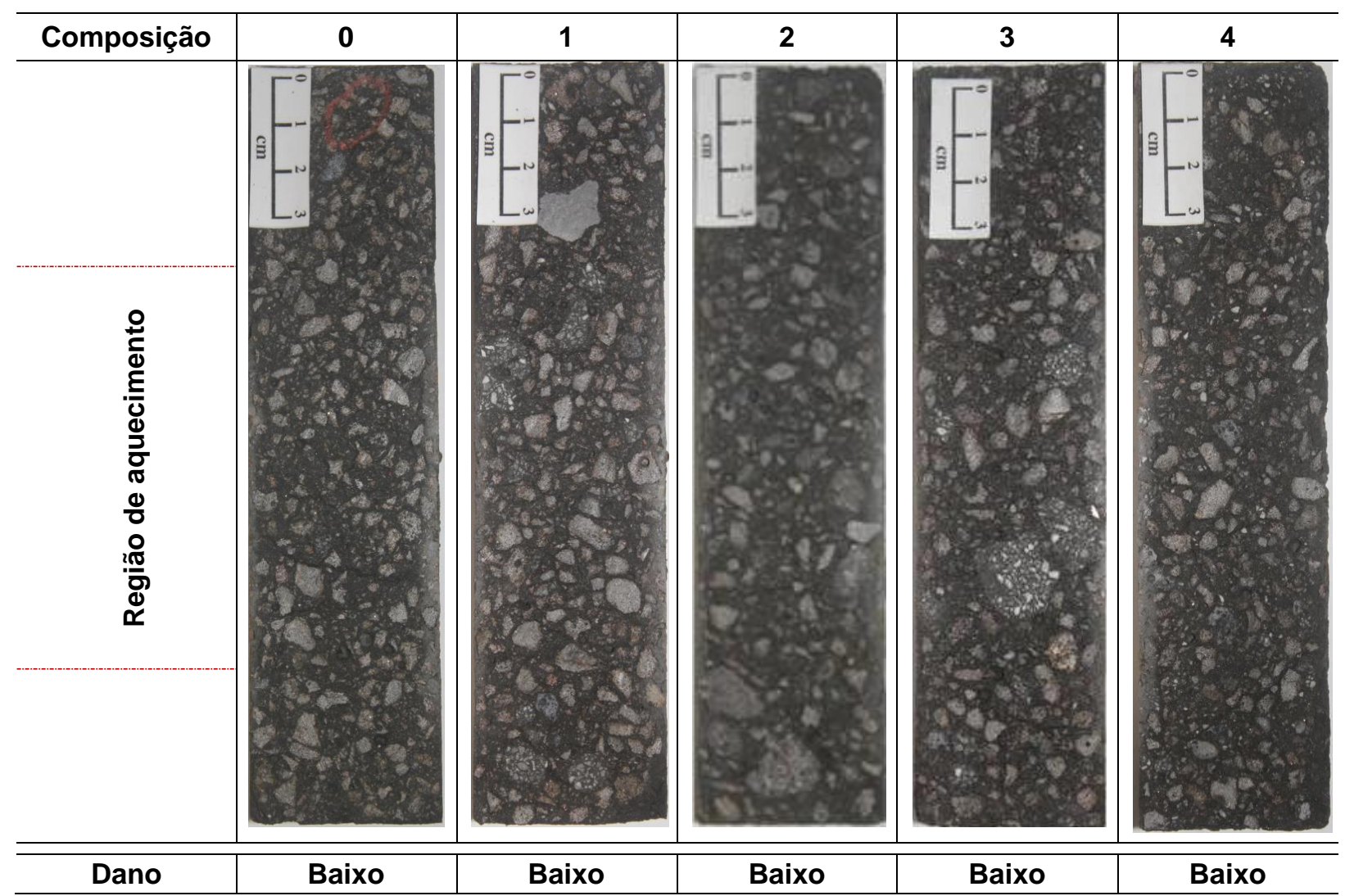

Figura 7. Fotografia da seção longitudinal dos corpos de prova após ensaio de choque térmico por chama (20 ciclos de aquecimento e resfriamento ao ar).

* Contribuição técnica ao 44 Seminário de Redução de Minério de Ferro e Matérias-primas, $15^{\circ}$ Simpósio Brasileiro de Minério de Ferro e 2ํㅗㅇósio Brasileiro de Aglomeração de Minério de Ferro, 15 a 18 de setembro de 2014, Belo Horizonte, MG, Brasil. 


\subsection{Ataque por Escória}

Os resultados mostraram que a diferença entre os índices de desgaste não foi significativa (figura 8). Não houve correlação entre a resistência à flexão a $1400^{\circ} \mathrm{C} \mathrm{e}$ a resistência ao desgaste por escória. Por exemplo, a composição 2 que apresentou menor valor de resistência à flexão a $1400^{\circ} \mathrm{C}(2,8 \mathrm{MPa})$ exibiu desgaste semelhante ao da composição 1 (3,4 MPa).

A superfície exposta à corrosão dos corpos de prova contendo agregados mais grossos (composições 1, 2 e 3) apresentou-se mais irregular, caracterizada por pequenos vales, com indícios de desgaste preferencial dos agregados reciclados (figura 9). Esse comportamento foi atribuído às solicitações mais severas impostas pelo ensaio de corrosão em forno rotativo, que envolve intensa oxidação e erosão. Essa consideração é reforçada pelo menor índice de desgaste do concreto contendo agregados mais finos (composição 4), apesar de conter maior quantidade de ferro total. Portanto, os agregados mais grossos são mais susceptíveis à oxidação por fases gasosas e erosão que ao desgaste por escória. Essa hipótese ganha importância quando se considera que a quantidade de antioxidante (SiC) nos agregados de carro torpedo é muito menor que a do concreto para canal de corrida. De uma forma análoga, os agregados de placa gaveta não contêm SiC. Entretanto, acredita-se que esse mecanismo de desgaste não deva prevalecer em escala industrial, principalmente na região do canal de corrida em contato com o gusa.

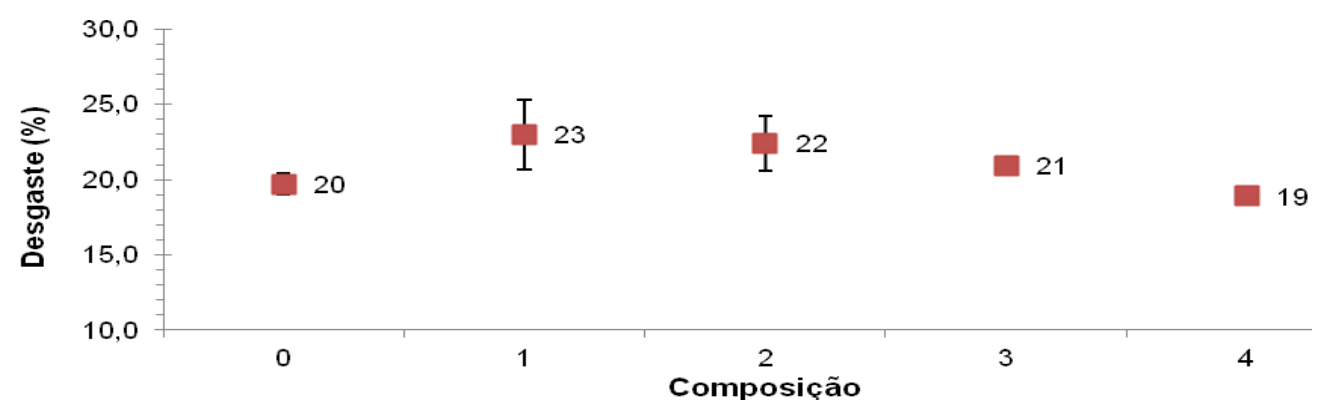

Figura 8. Índice de desgaste por ataque por escória em forno rotativo $\left(\bar{x} \pm \sigma_{n-1}\right)$.

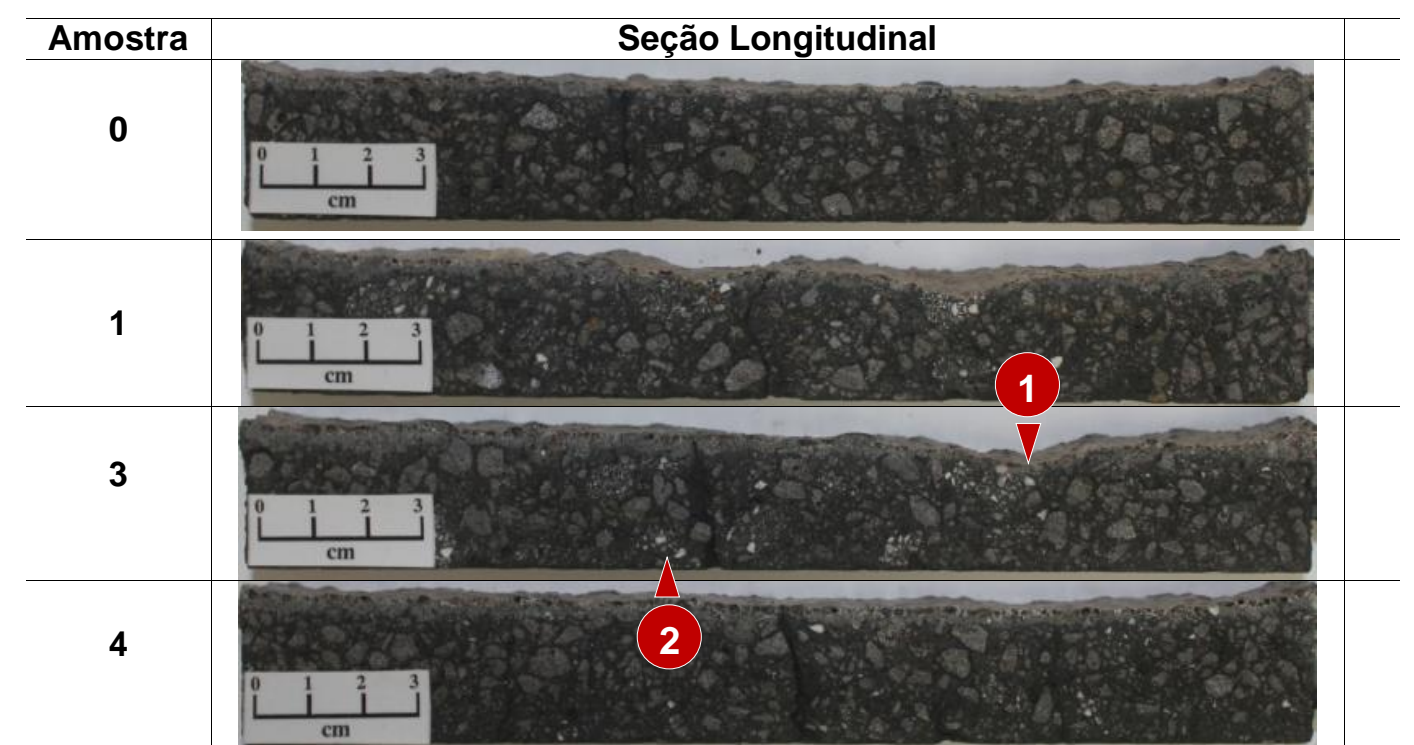

Figura 9. Fotografia da seção longitudinal dos corpos de prova após ensaio de ataque por escória em forno rotativo: vales (1) e agregados reciclados de placa gaveta (2).

* Contribuição técnica ao 44 Seminário de Redução de Minério de Ferro e Matérias-primas, 15 Simpósio Brasileiro de Minério de Ferro e 2ํ Simpósio Brasileiro de Aglomeração de Minério de Ferro, 15 a 18 de setembro de 2014, Belo Horizonte, MG, Brasil. 


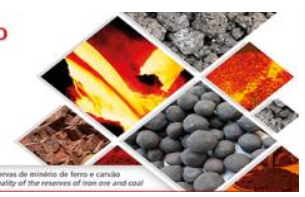

\section{CONCLUSÕES}

Os resultados de propriedades físicas e químicas indicaram que a adição de $10 \%$ de agregados reciclados de placa gaveta e carro torpedo, de $4 \mathrm{~mm}$ a $18 \mathrm{~mm}$, não afetou de forma significativa o desempenho do concreto para canal de corrida. Além disso, os agregados mais finos de placa gaveta, de $1 \mathrm{~mm}$ a $6 \mathrm{~mm}$, podem ser utilizados com sucesso. Assim, os agregados grossos e a fração fina gerados no processo de britagem podem ser mais bem aproveitados.

A reciclagem de refratários ganhou grande impulso na Usiminas nos últimos anos com o desenvolvimento de processos simplificados para beneficiamento da sucata refratária e emprego de práticas atrativas e seguras. Esses esforços têm contribuído de forma substancial para aumentar a eficiência da manutenção e melhorar o desempenho ambiental da Empresa.

\section{REFERÊNCIAS}

1 Hanagiri S, Shimpo A, Inuzuka T, Matsui T, Aso S, Matsuda T, Nakagawa H. Recent Improvement Of Recycling Technology For Refractories. Nippon Steel Technical Report, 2008; 8: 93-98.

2 Hagiwara M, Ishihara M, Fujieda T, Tanaka M. Recycling Used Sliding Nozzle As A Raw Material For $\mathrm{Al}_{2} \mathrm{O}_{3}-$ Sic Brick. Journal Of The Technical Association Of Refractories, 2004; 24(1): 88-71.

3 Yamada K. Recycling Of Refractories In Steelworks. Journal Of The Technical Association Of Refractories, 2004; 24(1): 72-74.

4 Abnt. Material Refratário Conformado - Determinação Da Variação Linear Dimensional Permanente Após Aquecimento. Método De Ensaio, Nbr 6225, Rio De Janeiro, 2013, 5 P.

5 Abnt. Produtos Refratários Conformados Densos E Isolantes - Determinação Do Módulo De Ruptura À Temperatura Ambiente. Método De Ensaio, Nbr Iso 5014, Rio De Janeiro, 2012, 5 P.

6 Abnt. Materiais Refratários - Determinação Da Resistência À Flexão A Quente. Método De Ensaio, Nbr 9642, Rio De Janeiro, 2012, 2 P.

7 Astm. Standard Test Method For Rotary Slag Testing Of Refractory Materials. Standard Test Method, Astm C 874, West Conshohocken, 2004, 3 P.

* Contribuição técnica ao 44 Seminário de Redução de Minério de Ferro e Matérias-primas, $15^{\circ}$ Simpósio Brasileiro de Minério de Ferro e $2^{\circ}$ Simpósio Brasileiro de Aglomeração de Minério de Ferro, 15 a 18 de setembro de 2014, Belo Horizonte, MG, Brasil. 